\title{
sciendo
}

\section{Constructivism and competitive intelligence, new economic model during Covid-19 crisis}

\author{
Mihail PĂDURARU \\ Bucharest University of Economic Studies, Bucharest, Romania \\ Intelligence Directorate for Defence Industry \\ mihail.paduraru@ro-intelligence.com
}

\begin{abstract}
Currently, the dynamics of new generation threats have deeply influenced the economic stability in several areas of the world, especially with the onset of the Covid-19 health crisis. Moreover, the nature and the plurality of the new hybrid risks and threats demands a stringent need to deepen the studies on new models used in competitive assessments.

This paper proposes integrating core ideas of constructivism into the new model of competitive intelligence in order to improve the process of economic resilience building.

That being said, the current research aims to bring into the light a complementary approach which could improve the competitive intelligence practices through economic constructivism.

The economic constructivist approach will provide additional conceptual tools to understand business and economic issues related to human consciousness, national identity, and interest formation after the state of entropy generated by the Covid-19 pandemic.

This academic approach aims to highlight several particular topics, such as the relationship between competitive intelligence and economic constructivism, as well as the implications of economic constructivism for competitive intelligence.
\end{abstract}

Keywords: competitive intelligence analysis; economic constructivism; security; critical thinking; errors.

\section{Introduction}

Against the background of eroding the internal economic and social balances all over the world, multiple changes to political and economic values were noticed.

Though often misconstrued among experts, constructivism as a concept is not a new or unknown approach.

ONE of the initiators of this school of thought, Nicholas Onuf, defined constructivism as a perspective on socio-economics inquiry instead of a theory in itself, as it constitutes a valuable tool for the analysis of widespread theories of empirical or normative nature.

From this perspective, Onuf appreciate that constructivism is applicable to all areas of socioeconomics inquiry and socio-economics studies.

Epistemologically, constructivism is built on the base of natural and humanitarian theories. Fundamental works on concepts such as empiriomonism, second order cybernetics, calculus, ecology of the mind and constructivist psychology, were produced by A. Bogdanov (Bogdanov, 2003), H. von Foerster (Foerster, 1973, 2003), G. Spenser-Brown (Spenser-Brown, 1974), G. Bateson (Bateson, 2005), J. Piaget (Piaget, 2004). Other notable works include the theory of social systems (Lumann, 2007) and bio-cognitive research (Maturana, Varela, 2001).

In relation to constructivism, J. Schumpeter argue that any analytic work, was preceded by a pre-analytic learning stage, which supplies the material to be analysed. (Schumpeter, 2004).

HENCE, the current paper aims to provide through an economic constructivist approach, some educated opinions and observations, which not only precede analytical work, but also enrich 
existing theories and can find their utility in the economic reality, while answering the following questions in this study.

These being said, the paper will emphasize the benefits of observing the economy in a new light, specific to the previous stage of science development, which is not dependent on conventional facts, methods and results.

Comparisons with other theories have been made, in order to test the correct understanding of economic reality.

Therefore, the current approach is concerned with explaining the evolution and psychological impact of ideas and norms, on economics, especially during the global health crisis that put humanity to the test at the beginning of the $21^{\text {st }}$ century.

That being said, the economic constructivist approach is not a new theory, that will change the economy, but a theory to understands it better.

\section{The economic analyst, the new constructivist observer of international economic relations}

From the classical standpoint, a theory is classified as scientific if it is characterized by objectivity and it is independent from the observer.

However, since the observer-independent analysis are not feasible in economics, one could assert that economic knowledge is subjective in nature, and objectivity in this case, is obtained through distributed subjectivity.

When measuring the attention paid to the observer, the main aspect to be considered is the reflexivity with its two component vectors.

The first one: the person's self-reference, [which takes into account the attention paid to the observer, as a biological object], aims to replace the concept of representative knowledge, with that of conclusive constructivism.

Second, the mutual self-reference, [which involve other people], is brought into debate. [I think that the others think like...].

The new age economist is considered a social actor who must understand the divergences between the processes of economic knowledge, as an individual economic activity, and the processes of economic knowledge as a social economic activity, as well as, the need for coordination between these two processes.

Since it is formed in accordance with the constructed values of humanity, which can deviate considerably from rational values, economic reality must become an object in itself.

The transformation of an "economic subject" into an "object for itself" is impossible without a prior inner coexistence, so the new age economist is at the same time both the subject and the object of the modern economic nature.

As a result, it can be concluded that this coexistence cannot be reduced and becomes the general condition for understanding the economic phenomena during the health crisis, as well as the main principle of each theoretical explanation.

Therefore, each theory must seek to reduce all arguments against the new economic model, generated during the health crisis, to the primary argument of the subject of cognition (economic analyst), which changes itself and metamorphoses into a living proof of new age economic phenomena.

The economic analyst's mission is to analyze an economic subject, to propose a certain planning, to criticize or methodically order the components, to conceive actions or give them 
meaning and to observe with his active capacity as an observer, the aspects that give rise to effects completely independent of his statements. This is why there are multiple interpretations of reality that cannot be fully defined.

So, if knowledge and ideas about economic aspects and economic environment are constructions that have a subjective character, then what can be said about the theories created by people who act on the basis of such constructions?

Then these theories are validated with arguments extracted from the empirical experience

PICBE | 1029 of the obtained economic reality, in order to justify the same economic theories, thus generating a circularity.

In this connection Schumpeter noted "if there is any motive that encourages us to see the facts in this way, and not otherwise, we cannot doubt that we will see them in the way we want" (Reisman, David, 2004).

How can one consider the effects which occur when assessing "objective" economic reality, if the whole economic context considered to constitute that reality, was conceived by the economic analyst consciousness before the question was asked?

Thus, it can be appreciated that cognitive function of the modern economist, adapts and leads to the establishment of an economic world based on experience, rather than to discover an ontological reality.

The concept of economic constructivism allows practitioners to build knowledge rather than passively absorb information.

As experiences arise in relation to the economic environment, the economist reflects on those experiences and builds his own representations, in which he incorporates new information and adds it to their pre-existing knowledge (mental schemes).

Therefore, knowledge of the essence or significance and social transformations depends on the providers of knowledge.

Moreover, in economic constructivism, knowledge is built progressively, at social and collective level. It is not inherently created from objects (inanimate or social) with which it is associated.

In light of what has been said, it can be stated that in economic constructivism, socioeconomic relations are reflexive models, built by people, through socio-economic knowledge, on which economic thinking is based.

Thus, it can be concluded that modern economists adapt to the social and economic environments in which they operate.

As Emanuel Adler explains, "This means that different collective meanings are attached to the material world twice, as social reality and as scientific knowledge.

In other words, knowledge is both a resource, that people use in their day-to-day life for the construction of social reality, as well as, the theories, concepts, meanings, and symbols that scientists use to interpret social reality."

However, true economic knowledge is that which manages to maintain the resilience and sustainability of an economic system, so as to ensure survival in an uninterrupted cycle.

The replacement of the concept of "true" with that of "resilience and sustainability" completely changes the orientation of the cognitive subject.

Cognitive judgment processes will not focus on identifying "true" or "false", "correct" or "wrong" arguments, but on that constructed economic knowledge and to identify those activities that can ensure the resilience and sustainability of the economic system.

Hence, in relation with constructed economic knowledge, the role of competitive intelligence "is to extract certainty from uncertainty as well as to facilitate the adoption of coherent 
decisions in an incoherent and unclear environment generated by an overload of contradictory data." (Kent S. 1969).

Increasing intelligence needs and the surfeit of data, have redirected the resolute efforts from seeking the information, $\rightarrow$ to unlock the truth, in a universe saturated with conflicting data and information.

\section{New economics model through a constructivist lens}

PICBE |

1030

Even though there are several approaches to economic constructivism and various schools of thought, all share core characteristics and premises.

The constructivist theory was born in the early 90 s, according to which states are socially constructed, which mean, interdependent in reaction to each other. Moreover, the theory also provides a ground basis for understanding the dynamics of non-state actors.

Hence, economic constructivism brings a significant contribution for the new models of competitive intelligence, used in the theory of economic international relations, through its ability to illustrate the causal connection (not only stated), between economic identities and economic interests of the actors.

For example, against the background of the Covid-19 pandemic, competition has intensified instead of cooperation. The race for sanitary equipment was highlighted and then the vaccine was the new goal in which each nation seemed to act on its own. In the same context, signs of cooperation were rarely observed and most often with more bilateral than multilateral values.

Constructivism can highlight how policies and economic behavior are influenced by cognitive processes, in individual or common interactions, as well as in social and economic relations between various actors.

To achieve this level of explanatory power, the constructivist approach must demonstrate that the observation of economic and social events, together with explanations of the actors' economic behavior patterns, are superior to other interpretations extracted from international relations teory and economic paradigms.

In contrast to conventional approaches to competitive intelligence models, which tend to focus on specific issues, related to the identification and development of diversified methods for obtaining a competitive advantage in a business, the economic constructivist approach provides an inner rather into various other dimensions, including: human economic consciousness, economic identity and economic interest formation.

Thus, economic constructivism and models of competitive intelligence have a common vision on the role of economic norms, actors and structures, as well as on the relationship between economic identities and economic interests.

This is the reason why the significance of economic and competitive intelligence models increases exponentially, when viewed through constructivist theoretical lenses.

Economic constructivism emphasizes that social and economic elements are created by humans and can be observed in the daily behavior of individuals, but have fluid characteristics and adaptable to the situational context, rather than being limited to a rigid structure established by economic policies.

In this context, constructivism asserts that the process of international economic politics alters economic interests and economic identity, in the international affairs system.

Thus, in contrast to the mainstream approaches to international economic relations, economic constructivism assumes that the interactions between actors generate economic interests 
and identity, while identity, in turn, becomes the basis of economic interests (Mercer, 1995: 231235; Katzenstein, 1996a: 2).

Economic constructivism also emphasizes the sociological concepts of ideas, norms, identity and culture, for it is through ideas, norms, rules, can be understood how actors shape their economic identities and redefine their economic interests (Finnemore, 1996: 128).

Hence, the constructivist concepts can be used in economic and competitive intelligence models for better understanding of many unexplainable interactions within international economic relations.

The power of ideas, the interplay between actors and their social context, the notion that actors, words, deeds and interactions, shape the kind of world in which they exist, and the world shapes "who actors are" and "what they want" (Ba and Hoffmann 2003, 15).

In fact, in competitive intelligence models, all theories that contain ideas about the nature of actors, the essence of the context around them and the quality of economic interactions between actors must be taken into account. These assumptions are needed to explain "why economic events occur" and "why actors choose to behave this way."

\section{The core elements of constructivism in relation to other theories in international relations and economics}

Economic constructivism aims to demonstrate or at least describe how economic identities are adopted by actors and how those identities could give rise to new economic interests of actors.

The concept of constructivism argues that the economic interests and identities of actors are flexible and depend on the context in which they find themselves.

The theory of economic constructivism emphasizes that the international system is based on specific characteristics, different rules, institutions, as well as societal and ideational meanings. Actors do not limit themselves to analyzing the material capacities of their neighbors, nor on cost / benefit analyzes when deciding what their economic behavior will be.

Instead, actors are influenced by the economic rules, meaning and economic ideas shared by their socio-economic context.

What is sustainable or unsustainable, right or wrong, possible or impossible is part of an actor's socio-economic context and these ideas shape the economic desires of the actors (what the actors want), the economic identity of the actors (who the actors are) and how the actors behave.

These beliefs are in stark contrast to those of the concept of realism or liberalism, which considers that actors have a more or less constant economic essence.

The actors have been and will always be interested in themselves, security conscious and hungry for power, according to realistic theory. Liberals will always be rational and concerned with maximizing economic gains.

Constructivists believe that actors are dynamic, and their economic identity and economic interests may change in context and over time. "Who are the actors" and "what do the actors want" is determined by the interactions with other actors and by the wider economic context in which they find themselves.

At some point, actors may be security-conscious and power-hungry, and in other contexts, interactions may cause actors to have different economic identities, economic interests, and economic behaviors. 
Changing ideas about themselves define the economic interests of actors, not the other way around, as social science theory states. Economic identities and interests are built on common ideas, and they are not found in data from nature, they are not timeless or unchanging.

If there will be no new ideas, new socio-economic constructions, new economic identities, then there will be no new economic interest, nor innovation and knowledge.

In order to give rise to a competitive advantage, it is necessary to know how the economic actors were created from a socio-economic point of view, how they perceive themselves, how they relate to each other, how mutually constructed economic identities are formed and how new economic interests are generated in response to economic identities.

Constructed economic identities, as well as their corresponding economic interests, are fundamental issues that need to be explained as this knowledge precedes strategic analysis and the means used in final thinking.

Economic constructions that aim - the change of the actor's economic identities and differentiated economic interests - are always variable, open to questions and problematic.

The concept of economic constructivism rejects the "as if" thinking of the predominant economic theory in which it is assumed, without evidence or explanation, that economic actors move on a fixed and rigid trajectory "as if" they want to get what the economic analyst specifically indicates as preferences, rather than what the subject of the investigation wants.

On the one hand, realists assume that economic actors interact (mainly) competitively with each other and will always use power to get what they want, to survive and thrive. In the realistic vision, the economic actors are in an anarchic context where material resources (technology and money) are the most important characteristics.

According to the realists, due to the global disorganization, the economic actors are threatened with elimination from the system, so they act to survive. For this reason, economic actors are forced to be security-conscious and suspicious in economic interactions in order to maintain a favorable balance of power with other economic actors. The realistic theory predicts economic crises, encourages the need for constant preparation for economic confrontations and considers alliances as transient.

On the other hand, liberals admit in advance that states have many common interests (economic gains from trade and cooperation being among the most important), but, like realists, they believe that actors will act in a selfish way.

Realists are unable to predict a convergence of selfish, private and collective preferences, while liberals are convinced that convergences can be achieved through socio-economic mechanisms assumed bilaterally.

The Liberals coordinate their efforts and converge on common gains and smart selfishness to overcome conflicting preferences through an ever-expanding market system.

They are less skeptical about the effects of global disorganization and believe that cooperation is possible when economic actors help each other to achieve common interests.

Following the above, this paper aims to emphasize the very important contribution that the concept of economic constructivism has brought to light by highlighting the limits of "as if" thinking.

Constructivists ask deep questions about who the economic actors are, how and why they behave in a certain way and what are their economic prospects.

"What if" economic actors will be able to cooperate and overcome their proposed selfishness during Covid-19 health crisis, and do so because they believe that cooperation is instrumentally beneficial and is a positive economic asset, which is valuable in itself. 
In a similar way, thinking "what if" places the observer (economic analyst) in a position to accept the possibility that economic actors often act in contradiction with the liberal economic expectation of selfishness and the selfish acquisition of material wealth.

For many liberal economists to act unselfishly would be tantamount to irrational action, defined by the conditioned expectations of the liberal model of the economic standard, that of the materially driven rational man.

The concept of economic constructivism argues that the interpretation of "economic reality"

PICBE |

1033 goes beyond conventional explanations of the actor's economic behavior, or of the rise and fall of all socio-economic systems, including the practices that support or degrade them.

As Wendt observes, "in both social and economic science, observation of the economic world is affected by human theories. But economic scientific theories alone, have the potential to become part of their economic world as well. Such transformations violate the assumptions of the causal theory of reference, since economic reality is being caused by economic theory rather than vice-versa." (Wendt, 2000).

Also, the concept of economic constructivism makes a clear distinction between causal and constitutive explanations of the economic actor's behavior.

In the conventional causal analysis, it is assumed that if " $\mathrm{X}$ causes $\mathrm{Y}$, one first, assume that, $\mathrm{X}$ and $\mathrm{Y}$ exist independently of each other. Secondly, it is assumed that $\mathrm{X}$ precedes $\mathrm{Y}$ temporarily and finally, we assume that for X, Y would not have already occurred." (Wendt, 2000).

This explanation essentially replicates Robert Dahl's widely cited attempt to operationalize the concept of "power", "what causes A to do something, which A would not otherwise do in the absence of the power exercised by B?" (Dahl,2007).

This is why, the concept of economic constructivism argues that economic ideas (norms, rules, meanings) have a strong impact and must be taken into account when explaining economic phenomena or /and economic actions, but also this new economic model, does not ignore other theories.

In the concept of economic constructivism, ideas play a central role, and by concatenation of material power vector with the power of economic ideas, results a new concept capable of explaining the dynamics of socio-economic phenomena of the present days.

In other words, it is well known that material power cannot be ignored, as well as, not all economic ideas are equally significant. In this context, the difference is made by - who claims what ideas.

\section{Beyond the economic dilemma}

The fundamental dilemma of economic constructivism is based on the understanding that the progress of the economy depends on a socially constructed rule formation.

These rules and regulations limit the economic actors' freedom of action (What and How it can be done and How it will be received).

All this time the economic actor depends on economic action (governed by these rules) if he wants to transform the secure rules of the economy.

Theorizing assumes that economic action and its generic dimension are circumscribed to socio-economic processes that could explain the specific ways in which economic action, regulates socio-economic relations in contemporary societies.

This theoretical assumption basically involves two components: the socio-political component of the economy, explains the way in which economic expectations are mobilized in relation to a situational context organized around a particular stake. The second component, aims 
to explain the differences of politico-economic reasoning and deals with the extended symbolic models from which the economic practice arises.

The politico-economic approach explores very explicitly the conceptual delimitations of economic formation, or in other words, the way in which economic practice articulates the reasoning behind the economy.

It can also integrate the process of economic or social formation into a broader cultural circumstance, which can highlight how a cultural society symbolically organizes its relationship with nature, with itself and with other societies.

By juxtaposing the concepts of competitive intelligence, with economic constructivism, theorizing means that intelligence must provide the necessary knowledge to explain the structured formation of economic action.

So, the question that arises concerns the methodology and the way to understand what is happening, rather than a critical question about how to intervene to secure the socio-economic areas.

The theory of economic constructivism engages the economic dilemma in a traditional way that separates the research question from the question "What to do?"

This does not mean that the last question is ignored, but the answer to the questions "Why?" and "How?" is a structured problem, and in an economic analysis, it is a precondition to answer the practical question.

This traditional way of dealing with the economic dilemma is just one side of the same coin. The other side, engages the socio-economic relations in a more direct way, without separating the question of economic analysis, from the practical one.

Consequently, constructivist approaches to economic model face two methodological problems: First, the existence of economic rules and norms must be validated and then, the impact of the economic rules and norms on behavioral economic outcomes must be demonstrated.

The problem emanates from an ontological perspective, with which economic constructivists analyze unobservable phenomena.

Thus, economic rules and norms are recognized as having an objective existence and are not seen only as economic ideas floating around people's heads.

In other words, economic rules and norms are assumed as common beliefs, which exist in the real world through the meaning they give to economic situations and the practices they push towards.

So, economic practices can be observed directly, but the economic beliefs they express cannot be observed as easily. Then, where can one draw knowledge about the existence of these economic beliefs?

Clearly, getting into the minds of the economic actors and knowing their economic beliefs is a formidable challenge for any economic analyst.

The concept of constructivism aims to identify solutions in causal theorizing. If the rules and norms cannot be fully complied with, then the causal relationship between the economic rules and the economic behavior cannot be conclusively established either.

Consequently, the way in which constructivism explains economic action depends on the theorizing of the mechanisms that produce those causal relations.

Thus, economic constructivists manage to expose elements that could not be observed by direct means (culture) and are able to outline elements that could be observed directly (behavior).

In this case, realists and liberals do not have converging visions, since their hypotheses is that economies are organized similarly from a structural standpoint. 
For example, Waltz states that "contending actors imitate the innovations contrived by the country of greatest ingenuity," and so "competition produces a tendency toward sameness of the competitors." (Waltz, 1979)

Realists describe a simpler dynamic: either states learn the best practice, or they go out of business. Barry Posen writes, "As in any competitive system, successful practices will be imitated. Those who fail to imitate are unlikely to survive." (Posen, 1993).

For realists, the best practice is determined and observed through success in battle. Thus, "It is the victorious system of every great war that sets the standard by which, all others measure themselves and which acts as the model imitated by all" (Resende-Santos,1996).

On the other hand, liberals regard any crisis as an impediment to actors pursuing a common interest. Without a higher official body to oversee and sanction regulatory breaches, some actors would be able to cheat on deals and thus, uncertainty would make actors reluctant to cooperate.

\section{The "added value" generated by constructivism for economic and competitive intelligence}

Economic constructivism in problematizing all theories of knowledge, with an emphasis on international relations and economic theories, reincorporates human values into the question of a theory of knowledge of human thought and action.

However, economic constructivists' use psychology and human consciousness in order to bring the constructed economic actors in the spotlight, shows a main weak point.

Economic actors as predetermined models could only interact socio-economically within a set of regulations, norms and institutions. Such mechanisms, as Onuf insists, provide "opportunities to act on the world" (Onuf, 2012).

One could change the perspective on economic hierarchies by looking at economic systems as networks (Popkov, Baturin, 2007).

Starting from this concept, an economic system includes several sub-networks on various levels. Thus, the economy could be described as a network within which different individual systems, interact with each other.

For example, an economic system can be described schematically in the form of a multinode network. Each node represents a sustainable system, and its density will reveal it as a network in itself. In this new network, everyone can represent an entity that, in turn, will become a network and so on.

Despite the variety of networks, elementary networks are limited to only three types: nodal ("tree" type), delimited and mixed.

Most commonly, economists strive to build these systems by connecting them into larger frames and arranging them by size, from large to small in a reverse pyramidal structure. Regardless, in our society these hierarchies are better described only as networks incorporated into other networks.

Viewed from a constructivism perspective, economic and competitive intelligence models are affected by a large number of factors, which are generically presented as adversaries of intelligence and lead to errors in this field of activity.

These factors are generated by the characteristics and nature of the human element, but also by the evolutions of the intelligence level, being a collection of mental limitations, contradictory dilemmas and imperatives, paradoxical interactions that often block the development of the intelligence process. 
The additional details about the variables already existing in the mental model and the information about other variables, which do not have a significant influence on the judgment, have a negligible impact on accuracy, but they form the mass of raw material, that observer need to work with.

In this context, a very important aspect for economists is to understand and become aware of their own lenses (mental models or shortcuts, biases or analytical assumptions), through which the gathered information is inherently filtered.

During the Covid-19 health crisis, the proliferation of data sources and the difficulty of verifying them in real time, led to decision errors, that did not occur because there was no data, but due to misinterpretation and poor analysis.

Understanding thinking errors from a constructivist perspective will improve the "naive psychology" of an observer and then the mechanisms of judgment will allow him much faster, to give meaning to the elements and relationships in the environment.

Moreover, the factors that pertain to the naive psychology of each human individual have the potential to distort the picture of reality "as it is" and stereotypes play a very important role in this regard. These are defined as, a mental energy saving mechanisms, processed either top-down, based on previously held information or bottom-up, through the automatic attention that explains why information inconsistent with previous expectations and stereotypes, is favoured.

Mostly, the stereotypes will favour the top-down strategy and thus, cover the gaps of real information about the socio-economic target.

Individuals pay more attention to information according to their expectations, memorize them more easily because their processing and reintegration into memory is easy and they interpret them in accordance with the stereotype.

On the contrary, unexpected information is appreciated as the exception to the rule and is forgotten in a short time.

Therefore, the reality is constituted by the whole set of socio-economic representations through which an observer gives meaning and consistency, to the existence.

The processes underlying the elaboration of representation systems are structured by cognitive schemes, through which the objects of social existence are structured into distinct groups, thus the reality becomes coherent and intelligible.

In light of previous statements, Elder and Paul (2005), argues that thinking consists of the following eight elements: goals, problems, points of view, information, inferences, concepts, implications, and hypotheses (Richard \& Elder, 2005).

According to the thesis of the socio-economic construction of reality, a person can admit the existence of reality or, more precisely, of realities, which is, the world made up of several realities.

This theory appeared at the beginning of applied psychology but was later articulated coherently in the writings of P. Berger and T. Luckman (1966).

The theory supports the inability of individuals to know the world "as it is", but only on the basis of what is said about it, based on the types of discourse (Berger and Luckmann, 1966).

Without denying the socio-economic reality, the theory postulates the existence of several spheres of reality, elaborated by individuals during the exchanges between them, which, for the most part, are not objective.

As a possible type, everyday reality is, [by reference to "other realities"], "the supreme reality" (Berger and Luckman, 1966: p36), organized around a ["here"] - space; and ["now"] time of the individual. 
The relation with the other realities is maintained, but "the conscience returns permanently to the supreme reality as from a trip".

The social stock of knowledge describes the integrated world, but differentiated according to the fields of familiarity and distance.

In other words, the inherent reporting of "here" and "now" determines a perception of socio-economic reality through a continuous string of standardizations, recurring patterns of interaction and thus knowledge is structured according to its relevance to the individual.

The system of belonging is regarded as the whole of the specific problems that concern the individual, corresponds with the vision of the world and translates into a selective perception.

Understanding the perspective offered by economic constructivism allows the definition of socio-economic representations as one of the possible forms of knowledge, a "reading grid" and a way of interpreting everyday economic reality.

The perspective proposed by social psychology accepts the absence of objective reality: the reality is represented by the subjects, reconstructed in their cognitive system and integrated in their value system; therefore, social representations are defined as "a form of knowledge, elaborated and shared socially, having a practical purpose and competing in the construction of a common reality for a social whole" (Neculau A., 1996: 129)

The attribution of causality is the cognitive process that induces a second coherence plan, the one that highlights the subjective ways of establishing the implicit causal relationships between people and socio-economic situations.

From a technical point of view, constructivism and competitive intelligence are new future economic models, which were born from the health crisis that humanity is going through and can be described as dynamic processes, oriented to specific events / problems, approached from different perspectives, allowing to understand / explain as a whole, some certain situation, with all the inherent risks involved.

\section{Conclusions}

The economic practice observed through a constructivist perspective emphasizes the way in which the new models of economic and competitive action are influenced by norms and values.

Moreover, the school of constructivist thinking proves to be one of the best choices to describe the paradigm shift of international economic relations during Covid-19 crisis, as well as the transformations in the identity of actors and in the formation of economic interests.

So, what changes, when the action principles of classical economy are challenged through new models of constructivist approaches?

Generally, shaping economic and competitive models through the lens of constructivism, show how economic interests arise within a common interaction process.

Economic identities are determined by the economic action processes, while the economic interests are given by the economic identity. The economic value is given by the economic actors' attention transferred towards economic interests.

As people start to think of economic interests, the definition of economy and competitive action will become - people-centred.

If expression of economic constructivism and competitive action model of economy makes a difference, then the question arises - What is this difference?

To provide an adequate answer, it can be appreciated that the difference is made by refinement and efficiency of the techniques and methods that can be used to explain the economic reality, which define failure or success of competitive intelligence action. 
More than that, such practices can help to define advanced knowledge designed to prevent and counteract any actions that pose a threat to any business or industrial segment operating in the economic circuit.

All knowledge is composed of social structures which guide the nature of knowledge and social significance. Both of these rely on human perception, which plays a decisive role in all human actions (Kubálková, 2016).

In this context new constructivist and competitive models of economy, must use the explanation and interpretation to evaluate the causes, conditions and current evolution of the new risks and threats.

By explanation and interpretation, causal relationships are established between different items, those relationships that can be supported by evidence and that can be certain, probable or possible.

Hence, in the new constructivist and competitive models of economy, there is a constant need for analysis which is a mental process, implicitly prone to subjectivity and limitations of human psychology and its success depends, categorically, on "how well analyst's think."

Therefore, the thinking in post-crisis must be educated to avoid mistakes that most people encounter.

In new models of economic constructivism, critical thinking represents the cognitive process of central significance in the reflection of the real, which, extracts and processes the information about the categorical and determinative relationships in the form of concepts, judgments and reasonings. All this can be made through abstractization and generalization, coordinated in mental actions.

However, human thinking is prone to distortions, prejudices and partisanship and the mind of the economic analyst is no exception.

Assumptions and biases remain major sources of analytical failures, affecting both observers and the analytical products they produce. This is because it is very difficult for a human person to realize his own prejudices and assumptions during economic and competitive analysis process.

Even in the case of an experienced observer, the reaction is to rely on the mental attachments created over the years of pre-crisis experience and which have served him, so far, so well, before the global crisis.

The judgement error take place when the observer does not conclude that, there is a stringent need to adapt the mechanisms and mental models of analysis, to dynamic and emerging environment, as well as, to new mentality, or individual and collective action, that occurred with the Covid-19 health crisis.

These psychological risks have also made their mark on the activity carried out by the public or private intelligence organizations.

Preparing specialists for competitive analysis applied to economic matters, should focus on trying to open the mental model of the observer with new ideas and norms, including gender analysis, to support reasoning.

Thus, they will be able to evaluate the problems from different perspectives and will develop enough space for alternative explanations.

Intelligence analysis is largely dependent on the ability to perceive and process data and information at the level of individual or collective human mind. 
The human being has an impressive network of sensors, which correspond to the six human senses and supports the function of analysis / interpretation / processing of information from the brain, which is why, any observer should question his assumptions as often as possible.

Experience has shown that, when analytical judgments prove to be wrong, the error did not occur, because the information was wrong, but because one or more wrong assumptions were unchallenged in the mental process carried out by the analyst.

In order to prevent errors, the observer has a duty to question the central hypotheses of the analysis and ask what might happen which would invalidate the hypothesis.

Also, the analyst must identify one or more alternative models, conceptual frameworks or different interpretations of data, which will be debated and analyzed by other colleagues with contrary opinions.

In other words, in new constructivist and competitive models, the cognitive processes should be adapted to economic reality by asking different kind of questions and change the perspective from which the economic phenomenon is analysed.

Brain training exercises should be performed as well, with the assumption that an unexpected event actually happened, then return to the initial situation to explain how this event could take place. Thus, proposed constructivist and competitive models should focus on answering questions aimed to $-H O W$ an economic situation can occur (modus operandi) and not to questions that target $I F$ that economic phenomenon will appear (the possibility of occurrence).

In addition, a mandatory practice in post-Covid-19-health crisis, constructivist thinking model requires the observer to imagine that he impersonates his opponent's economic identity. What decision would he make? This exercise will take place under the resolutive condition of coherence and decisional pragmatism, avoiding as much as possible the Mirror Imaging bias, which assume that other economic actors will act in the same way the observer would, given similar circumstances.

Also, a good practice can be to support a minority point of view in order to discover as many conflicting interpretations, and alternative hypotheses.

Hence, critical thinking plays a particularly important role in new post-crisis economic and competitive models of economy and such cognitive approach make possible to mitigate the errors of judgment generated by the observer's predefined ideas.

Moreover, economic and competitive models of economy based on constructivism and critical thinking, will exponentially improve the analytical reasoning, as well as perception reassessment.

Therefore, a constructivist assessment of the facts and evidence will provide a clearer view of the situation and increased coherence of the analysis, thus significantly reducing the risk of being deliberately misled by opponents.

Any analytical judgment from a multidisciplinary perspective will ensure the transparency of the thinking mechanism, so that all stages of the reasoning can be explained, easily tracked and revised.

In this way, both the economic and competitive producers, and consumers of the intell, will no longer focus on the result of the analysis, but on the process of its elaboration.

This will also generate more efficient analytical structures, which can be easily evaluated later at each stage of the process. 


\section{References}

Ba, A., \& Hoffman, M.J. (2003). Making and Remaking the World for IR 101: A Resource for Teaching Social Constructivism in Introductory Classes, International Studies Perspectives 4.

Bateson, G. (2005). "Shagi v napravlenii ecologii razuma. Izbrannye statji po teorii evolutsii i epistemologii" [Steps towards ecology of mind. Selected articles on evolution and epistemology theory]. M., Komkniga [In Russian].

PICBE |

1040

Berger, P.L., \& Luckmann, T. (1966). The Social Construction of Reality: A Treatise in the Sociology of Knowledge, Penguin Books, available at https://archive.org/details/Berger SocialConstructionOfReality_201901/page/n7/mode/2up.

Benedek, W. (2008). Human Security and Human Rights Interaction. Moufida Goucha and John Crowley, eds., Rethinking Human Security, available at https://download.e-bookshelf.de/ download/0000/5988/71/L-G-0000598871-0015302359.pdf.

Bogdanov A.A. (2003). Empiriomonizm: stat'i po filosofii [Empiriomonism: Articles on Philosophy] (Moscow: Respublka).

Bizadea, C., \& Andrei, V. (2015). Risk Analysis - A Practical Perspective, "Mihai Viteazul" National Academy of Information Publishing House, Bucharest.

Davis, J. (2002). Sherman Kent and the Profession of Intelligence Analysis, Occasional Papers, Volume 1, Number 5, The Sherman Kent Center for Intelligence Analysis, available at https://www.cia.gov/library/kent-center-occasional-papers/vol1no5.htm.

Dahl, R. (2007). The Concept of Power. Behavioral Science. 2. 201-25. 10.1002/bs.3830020303.

Foerster, H. (2002). Understanding Understanding: Essays on Cybernetics and Cognition.

Finnemore, M. (1996). National Interests in International Social Theory, Cornell University Press, New York.

Resende-Santos, J. (1996). "Anarchy and Emulation of Military Systems: Military Organization and Technology in South America, 1870-1930", Security Studies, 5(3).

Katzenstein, P. J. (1996). Cultural Norms and National Security: Police and Military in Postwar Japan. Cornell University Press, Ithaca, New York.

Waltz, K. (1979). Theory of International Politics (Reading, Mass.: AddisonWesley).

Kubálková, V., Onuf, N., \& Kowert, P. (2016). International relations in a constructed world / Vendulka Kubálková, Nicholas Onuf, Paul Kowert, editors. Routledge.

Lumann, N. (2007). "Sotsialnye sistemy. Ocherk obschey teorii" [Social systems. Common theory outline]. //Saint-Petersburg, "Nauka". [In Russian].

Maturana, H, Varela, F. (2001). "Drevo poznaniya: biologicheskiye korni chelovecheskogo ponimaniya" \{The tree of knowledge: biological roots of human comprehension\}.// Transl.from Eng.by J.A.Danilov. M.: Progress-Traditsia. [In Russian].

Mercer, J. (1995). Anarchy and Identity.International Organization, Vol. 49, DOI: https://doi.org/ $10.1017 /$ S0020818300028381.

Neculau A. (1996). Social Psychology-Contemporary Aspects, Iaşi, Polirom Publishing House.

Onuf, N. (2012). World of Our Making: Rules and Rule in Social Theory and International Relations. World of Our Making: Rules and Rule in Social Theory and International Relations. 1-340. 10.4324/9780203722428.

Patrascu, D. (2016). The Impact of Errors on Intelligence Analysis, Crime Investigation Journal, Volume IX - number 1, p. 733.

Piaget, J. (2004). "Geneticheskaya epistemologiya" [Genetic epistemology]. — SPb.: Piter. [In Russian]. 
Posen, B. (1993). "Nationalism, the Mass Army, and Military Power", International Security, $18(2)$.

Reisman, D. (2004). Schumpeter's Market: Enterprise and Evolution. 10.4337/9781845420857.

Richard, P., \& Elder L. (2005). Critical Thinking Competency Standards, https://www.critical thinking.org/resources/PDF/CT-competencies\%202005.pdf.

Spenser-Brown, G. (1974). «Laws of Form»//BookMasters (Ashland,Ohio). ISBN: 0-9639899-0-1.

Sherman Kent (1969). Estimates and influence, Foreign service Journal, n. 46, april 1969, p. 16 available at https://archive.org/details/sim_foreign-service-journal_1969-04_46_5/page/n3 /mode/2up?q=Foreign+service+Journal\%2C+n+46\%2C+april+1969.

Sherman Kent, Strategic Intelligence for American World Policy, available at https://archive.org/ details/in.ernet.dli.2015.86810.

Wendt, A. (1992). Anarchy is What States Make of It: The Social Construction of Power Politics. International Organization, 46(2), available at https://www.cambridge.org/core/journals/ international-organization/article/anarchy-is-what-states-make-of-it-the-socialconstruction-of-power-politics/B03BC7C9AAC5211B6DC319C077C1A854.

Wendt, A. (1994). Collective Identity Formation and the International State, American Political Science Review, 88(2), available at https://www.jstor.org/stable/2944711?seq=1.

Wendt, A. (1995). Constructing International Politics, International Security, 20(1), available at https://www.researchgate.net/publication/265960638_Constructing_International_Politics.

Wendt, A. (2000). A Social Theory of International Politics. Social Theory of International Politics. 26. 10.1017/CBO9780511612183. 